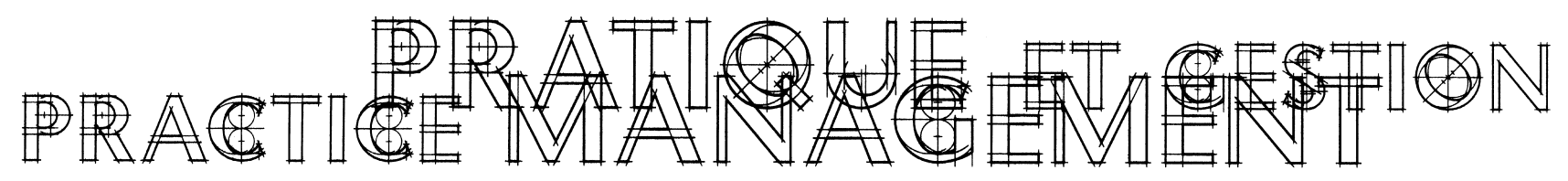

\title{
Take Your Practice to the Next Level - Part 1
}

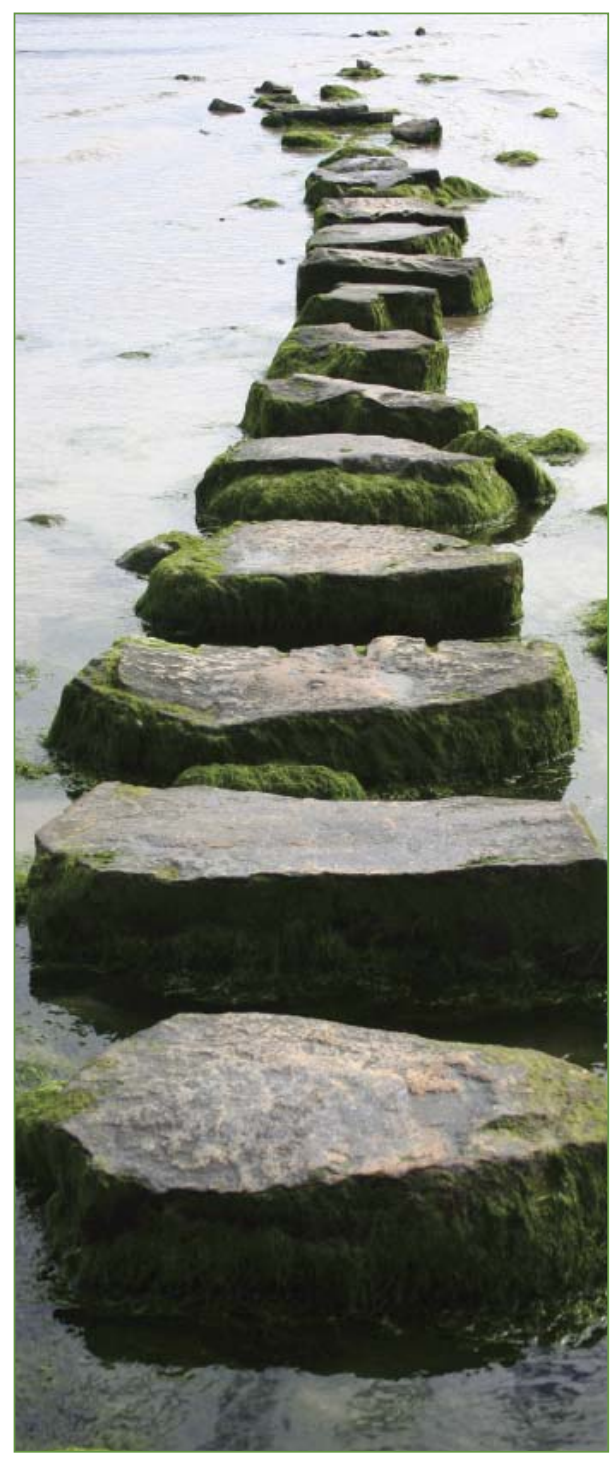

T $\mathrm{n}$ his book "The E-Myth Revisited", author Michael Gerber provides compelling arguments as to why businesses fail or never live up to their full potential. As I read it, I felt there were numerous parallels in the optometric practice. Although practices rarely actually fail to the point where they fall into bankruptcy, many do not live up to their earnings potential and owners find themselves struggling with the day-today operations. They hit a wall and practice life is not enjoyable anymore.

The typical cycle sees the optometrist starting out excited about putting into practice what he has learned in university, some terror as he starts, then over the years he moves into exhaustion and burn-out as he gets busier and tries to do all tasks. Then finally despair when he realizes his dream practice has turned into a job. However, it doesn't have to be that way.

Gerber's book suggests that there are three aspects to any business owner. There is the entrepreneur who is the idea person, the visionary. He provides the vision for what his dream practice should look like. There is the manager who will put processes in place to keep things running smoothly. As a manager he is pragmatic and provides the order necessary to get things done effectively and efficiently. Finally, there is the technician who is the doer and gets things done anyway he can, he just wants to get the job done.

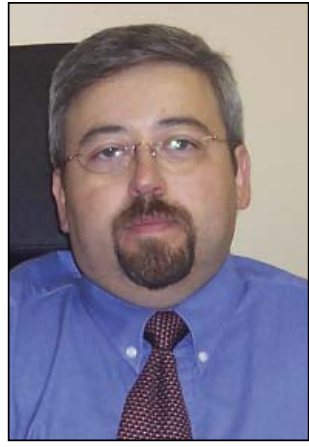

Alphonse Carew $\mathrm{BSC}, \mathrm{OD}, \mathrm{MBA}$ 


\section{PRACTICE MANAGEMENT



These three personalities are necessary for a business to be successful. The entrepreneur to provide the overlying mission of the practice, forward thinking and reacting to competitive forces to provide the best practice for the patients. The manager who provides the rules so things get done, on time and in the right manner, dealing with staffing issues, schedules, banking matters, etc. The technician to actually do the work of seeing patients, taking care of their needs.

The problem arises when these three aspects of the practice owner are in conflict, which is often. The dreamer entrepreneur can't be bothered with the pragmatic management concerns, nor the day-to-day handling of patients that the technician has to do. The manager likes to put things in specific boxes, which runs contrary to the visionary entrepreneur and only frustrates the technician. The technician has no interest in the dreamer's ideas or the manager's rules, he just wants to get things done.

The practice actually needs the three of these characteristics, usually at different times and for different jobs, to be successful. In the typically practice with a solopractitioner owner, only one of these personality traits are dominant and over time this trait will take over. For most people their dominant trait is the technician. I suspect given the nature of our work and training, optometrists likely have this as their dominant trait in a greater ratio than the general population. As optometrists we understand the technical aspects of our work much more so than the managerial or entrepreneurial roles, and this could be our greatest liability. Over time as the practice gets busier the business of just getting the job done takes centre stage. Thoughts on how to prepare the practice for future growth, and how to best compete in the marketplace are pushed to the side. Management rules and processes that take much time and effort are forgotten as our technician's role concentrate on getting through the day.

As the practice gets even busier the technician optometrist begins to see his day filled with patients to take care of, which is somewhat comforting to our technician trait. However, while this is being addressed other office administration tasks are being left behind. Soon these unattended task show up as staff discontent and practice stagnation. The practice starts to loose its competitive edge as the ideas of the forward thinking entrepreneur are stifled. Financially the practice may still be doing $\mathrm{OK}$, but it is not growing and not living up to its full potential.

In order take your practice to the next level you need to support the manager and entrepreneur traits in you, alternately you can seek advice from, or hire someone for these positions. More on that in the next issue of the Canadian Journal of Optometry.

\section{PATIENT TESTIMONIALS NEEDED}

CAO is preparing for October Eye Health Month (EHM) and needs your help to locate patients willing to promote preventive eye health examinations to Canadians. Contact the national office at ehm@opto.ca or (888) 263-4676 ext. 213 to let us know about compelling patient testimonials including:

$\rightarrow$ a serious and correctable eye condition/health conditiondetected through a routine eye exam ;

$\rightarrow$ a patient diagnosed with glaucoma or cataracts (or other age-related) condition at a younger age than typical ;

$\rightarrow$ a patient 'too late' to protect his / her vision because he / she experienced no signs / symptoms ;

$\rightarrow$ willingness to discuss eye condition and experience of regular visits on camera (CAO can assist with details).
